\title{
Chemical fractionation of trace elements in mangrove sediments from the Songkhla Lake, Thailand using BCR technique
}

\author{
Siriporn Pradit ${ }^{\mathrm{a}, \mathrm{b}, *}$, Noor Azhar Mohamed Shazilic, Manasawan S. Pattaratumrong ${ }^{\mathrm{a}, \mathrm{b}}$, \\ Ponlachart Chotikarn $^{\mathrm{a}, \mathrm{b}}$, Mathinee Yucharoen ${ }^{\mathrm{a}, \mathrm{b}}$, Prawit Towatana ${ }^{\mathrm{a}, \mathrm{b}}$ \\ a Marine and Coastal Resources Institute, Prince of Songkla University, Hat Yai, Songkhla 90110 Thailand \\ b Coastal Oceanography and Climate Change Research Center, Prince of Songkla University, Hat Yai, \\ Songkhla 90110 Thailand \\ c Ocean Research Institute, Universiti Malaysia Terengganu, Kuala Terengganu 21030 Malaysia
}

*Corresponding author, e-mail: siriporn.pra@psu.ac.th

Received 19 Mar 2018

Accepted 30 Oct 2019

\begin{abstract}
The aim of this work was to determine the concentration of trace elements ( $\mathrm{Zn}, \mathrm{As}, \mathrm{Cd}$ and $\mathrm{Pb}$ ) in mangrove sediments using the European community bureau of reference (BCR) sequential extraction method. The sampling was conducted in August 2016 at 8 stations of Songkhla Lake in southern Thailand. Trace element concentrations were determined using the inductively coupled plasma mass spectrophotometer (ICPMS). Zn (37.20-64.42\%) and Cd (63.44-77.50\%) were found dominant in the acid-soluble fraction (F1). Pb (62.01-89.48\%) was detected dominantly in reducible fraction (F2). As (49.92-73.45\%) was found dominant in F2 (at stations 2, 4, 6, and 8) and in oxidizable fraction (F3) with the concentrations of 48.71-68.02\% (at stations 1, 3, 5, and 7). All trace elements ( $\mathrm{Zn}$, As, Cd, and $\mathrm{Pb}$ ) were bound to the bioavailable fractions (first three fractions) and were low in residual fraction (F4). Calculation of ecological risk assessment of Cd revealed that the individual concentration factor (ICF) $>6$, the global concentration factor (GCF) $>24$ and the risk assessment code (RAC) $>50 \%$ in all stations were classified as high concentration and very high risk for aquatic organisms.
\end{abstract}

KEYWORDS: ICPMS, bioavailability, sequential extraction, risk assessment, trace elements

\section{INTRODUCTION}

Mangroves are potentially large depositories of sediment-associated trace metals due to their low redox potential and significant amount of $\mathrm{H}_{2} \mathrm{~S}$ present ${ }^{1}$ making them important to assess the mobility of trace metals in such environments ${ }^{2}$. Mangrove sediments are anaerobic and reduced, as well as being rich in sulphides and organic matter. Thus, they are useful in retaining heavy metals from anthropogenic and industrial pollutants. The total metal content of the sediments may not be able to provide a clear picture of the metal loadings and their behavior (such as mobility, toxicity, and bioavailability) with changing environmental conditions ${ }^{3}$. Occasionally, in function of physical and chemical changing of environments, metals can be released into pore water and reach aquatic biota ${ }^{4}$, where they may suffer bioaccumulation and biomagnification, as is the case of $\mathrm{Hg}^{3}$. In sediments, heavy metals are present in different geochemical forms which determine their mobilization capacity and bioavailability ${ }^{5}$. Assessment of heavy metal contamination of the coastal environment based on total metal concentration is not sufficient for an understanding of their environmental behavior since only a fraction of the total metal content is available for biological processes. Sequential extraction can provide better information about the identification of the main binding to the particulates and the phase associations of elements in sediment ${ }^{6}$.

Thus, numerous sequential extraction methods have been developed according to the type of reagent being used as an extractant, the experimental conditions applied and the number of steps involved to achieve different chemically bound fractions ${ }^{7,8}$. Dynamic metal speciation analysis in aquatic ecosystems is emerging as a powerful basis for development of predictions of bioavailability and reliable risk assessment strategies ${ }^{9}$. Consequently, besides measuring their total concentrations, determining the geochemical fractionation of metals in 
sediments is equally important in assessing their potential toxicity and threat to ecosystems ${ }^{10,11}$.

Songkhla Lake is a downstream area that receives water from various rivers at upstream areas of the Songkhla Lake Basin. There are various land uses that have the potential to release heavy metals ( $\mathrm{Zn}, \mathrm{As}, \mathrm{Cd}$, and $\mathrm{Pb}$ ) such as abandoned mining areas, shipyards for repairing and painting boats, agricultural areas with pesticide application and various communities around the lake basin. The activities of the aforementioned areas are the potential sources of heavy metals that will be released to downstream of the lake. Therefore, in recent decades several researches have been conducted to study the total concentrations of the heavy metals and reported the detection of various heavy metals in the sediment of Songkhla Lake. However, it is well known that the total concentrations of various metals detected in sediment in the environment cannot represent the level of toxicity to the health of living organisms including humans accurately and clearly. That is due to the amounts of the metals present in the sediment are mostly not in soluble or exchangeable forms (species), they are not available for biological processes and therefore there is little chance of being toxic to the organisms and threat to ecosystems. At present, there are very few studies (or even no published work) regarding the species of heavy metals present in the sediment of Songkhla Lake to provide a clear and accurate assessment of the severity level of heavy metal contamination in such sediment. Therefore, the aims of this study were to analyze the metal speciation for determining bioavailability of $\mathrm{Zn}$, As, $\mathrm{Cd}$, and $\mathrm{Pb}$ in mangrove sediments of the Songkhla Lake using modified European community bureau of reference (BCR) sequential extraction procedure ${ }^{12}$.

\section{MATERIALS AND METHODS}

\section{Study area}

The study area is the mangrove area in the Songkhla Lake. The Songkhla Lake is a coastal shallow lagoon, located in the southern part of Thailand with a surface of approximately $1042 \mathrm{~km}^{2}$. The average depth of the inner, middle and outer sections of lake is about 2, 1.5, and $1.5 \mathrm{~m}$, respectively. Salinity in the Songkhla Lake ranges from fresh water in the northern most to saline water in the outer section. The outer section is connected to the sea of the Gulf of Thailand through a deep and narrow outlet at Songkhla city. Several streams are flowing into the Lake. Two important canals are located in the outer section of the Lake. Firstly, U-Taphao canal which is the main source of freshwater draining into the outer part, with a length of $68 \mathrm{~km}$, originating from the Sadao district, in the Songkhla province. The canal is flowing through a large city (Hat Yai) before entering the lake. Secondly, Phawong canal is a short canal with a length of around $5.5 \mathrm{~km}$ and both sides of canal are densely covered with the mangrove trees.

The total of 199 industrial plants (metals, metal products, machinery) are located in Songkhla province $^{13}$ and only the Khlong U-Taphao basin serves a total of 110 factories ${ }^{14}$. The population of Songkhla province in December 2015 is approximately 1410577 people $^{13}$. with a population of 719927 people belonging to the 4 districts adjacent to the study area. At present, the condition of Songkhla Lake is deteriorating due to many environmental problems such as waste water, mangrove deforestation and increases of shrimp farms around the lake. However, from the Lansat TM satellite data in 1991, the mangrove forest in Songkla Lake is approximately 5620 ha but it is presently found only a small patch and expected to not exceed 1600 ha attributed to the outbreak of shrimp diseases resulting in substantially abandoned shrimp farms ${ }^{15}$. Mangrove forests in the Songkhla Lake basin found in Songkhla province are emerging mangrove forests. The mangrove forests are found at the mouths of the rivers and in the areas that are mostly muddy. The dominant mangrove species in the middle part of the lake is Sonneratia caseolaris whereas the dominant ones in the outer section of the lake are Rhizophora apiculate and Rhizophora mucronate.

\section{Sample collection}

The mangrove sediment samples were collected in August 2016 from eight stations at the Songkhla Lake. Stations 1 and 2 are in the middle section of the lake and the dominant mangrove plants is Sonneratia caseolaris while station 2 is Rhizophora apiculata. Stations 3 and 4 are located at Kuannieng district with the dominance of Rhizophora apiculata vegetation and Soneratia caseolaris, respectively. Stations 5 and 6 are situated near to each other and in front of Phawong canal. Station 5 has dominant vegetation of Rhizophora apiculata whereas there is mostly Soneratia caseolaris at station 6. Station 7 at Yoh island, the dominant plants is Rhizophora apiculata, while at station 8 located at the mouth of U-Taphao canal, Soneratia caseolaris is the predominant plant species. Triplicates of sediment samples were collected at each site at a depth of $10 \mathrm{~cm}$ 
Table 1 Value of trace metals ( $\mathrm{Zn}, \mathrm{As}, \mathrm{Cd}, \mathrm{Pb}$ ) of certified sediment material (SRM 1646a)

\begin{tabular}{lcccc}
\hline No & Element & $\begin{array}{r}\text { Certified } \\
(\mathrm{mg} / \mathrm{kg})\end{array}$ & $\begin{array}{r}\text { Observed } \\
(\mathrm{mg} / \mathrm{kg})\end{array}$ & $\begin{array}{r}\text { Recovery } \\
(\%)\end{array}$ \\
\hline 1 & $\mathrm{Zn}$ & 48.90 & 44.60 & 91 \\
2 & $\mathrm{As}$ & 6.23 & 5.70 & 91 \\
3 & $\mathrm{Cd}$ & 0.15 & 0.13 & 87 \\
4 & $\mathrm{~Pb}$ & 11.70 & 11.94 & 102 \\
\hline
\end{tabular}

using hand corer at $1 \mathrm{~m}$ distance from the mangrove plant bushes. The reason that the samples were collected at $0-10 \mathrm{~cm}$ depth because the aim of this study was to investigate the current horizontal metal diffusion or accumulation in the surface sediment mostly occurring at $10-15 \mathrm{~cm}^{16}$. The samples were mixed and composited by hand and stored in clean plastic bags for transportation to the laboratory. The $200 \mathrm{~g}$ wet sample was put on a tray and then oven dried at $50^{\circ} \mathrm{C}$, homogenized and grinded in a mortar and sieved through a $1 \mathrm{~mm}$ nylon sieve and then stored in plastic zip locked bags with label and kept in desiccators prior to further analysis.

\section{Total metal concentration analysis}

Approximately $0.1 \mathrm{~g}$ of sediment was weighed in the Teflon digestion bomb, digested in an acid mixture $\left(5 \mathrm{ml} \mathrm{HCl}, 8 \mathrm{ml} \mathrm{HNO}_{3}\right.$, and $\left.2 \mathrm{ml} \mathrm{HF}\right)$ and analyzed for heavy metals following the published methodologies of Noriki, et $\mathrm{al}^{17}$. The heavy metals were then measured by a ICPMS (Perkin Elmer Elan 9000). The sediment certified reference material; SRM 1646/estuarine sediment was similarly analyzed to validate the accuracy of the analytical procedure. The actual and observed values with the percent recovery for the certified sediment material (SRM 1646a) were displayed in Table 1, which demonstrated the validity of the methods applied.

\section{Sequential extraction}

Sequential extraction was performed using the revised BCR protocol ${ }^{12}$, briefly described as follows.

Step 1 (Fraction 1, exchangeable and acid soluble fractions): $40 \mathrm{ml}$ of $0.11 \mathrm{~mol} / 1$ acetic acid was added to $1 \mathrm{~g}$ of the air-dried sediment sample in a $50 \mathrm{ml}$ polyethylene centrifuge tube. The tube was shaken for $16 \mathrm{~h}$ at room temperature at a speed of $23 \pm 1 \mathrm{rpm}$. The extract was separated from the solid residue by centrifugation (3000 rpm for $20 \mathrm{~min}$ ), decanted into a polyethylene bottle and stored at $4^{\circ} \mathrm{C}$. The residue was washed by shaking with $20 \mathrm{ml}$ of distilled water for $15 \mathrm{~min}$, centrifuging after which the supernatant was discarded. This step is for determining the dissolved and exchangeable metals.

Step 2 (Fraction 2, reducible fraction): $40 \mathrm{ml}$ of $0.5 \mathrm{~mol} / 1$ hydroxylamine hydrochloride (adjusted to $\mathrm{pH} 1.5$ by addition of a fixed amount of $\mathrm{HNO}_{3}$ ) was added to the residue from Step 1 and the extraction performed as in Step 1 above. This step is for analyzing the metals bound to carbonate and Fe-Mn oxides.

Step 3 (Fraction 3, oxidizable fraction): $10 \mathrm{ml}$ of $8.8 \mathrm{~mol} / 1$ hydrogen peroxide was added in aliquots to the residue from Step 2. The vessel was covered loosely and the contents digested at room temperature for $1 \mathrm{~h}$ with occasional agitation. It was then placed in a water bath and digested at $85^{\circ} \mathrm{C}$ until the volume was reduced to less than $3 \mathrm{ml}$. Another $10 \mathrm{ml}$ of the hydrogen peroxide was added, and further heated to near dryness. Thereafter, $50 \mathrm{ml}$ of $1.0 \mathrm{~mol} / \mathrm{l}$ ammonium acetate (adjusted to $\mathrm{pH} 2$ with $\mathrm{HNO}_{3}$ ) was added and the extraction performed as in the previous steps. This step is for determining the metals bound to organic matter.

Step 4 (Residual fraction): The residue from Step 3 was transferred into a suitable vessel and the metal content determined by microwave-assisted digestion with aqua regia. This step is for analyzing the metals contained in their primary and secondary minerals.

The trace element ( $\mathrm{Zn}, \mathrm{As}, \mathrm{Cd}$, and $\mathrm{Pb}$ ) content of each fraction was analyzed using ICP-MS model Perkin Elmer Elan 9000.

\section{Redox potential (Eh) and $\mathrm{pH}$ measurement}

The measurements of redox potential (Eh) and $\mathrm{pH}$ in the mangrove sediments were performed in the field with a combined $\mathrm{pH} / \mathrm{Eh}$ meter (IQ $140 \mathrm{pH} / \mathrm{mV} / \mathrm{Temp} / \mathrm{ORP}$ ). Redox was measured using a Pt redox electrode combined with a $\mathrm{Ag} / \mathrm{AgCl}$, $[\mathrm{KCl}]=3 \mathrm{~mol} / \mathrm{l}$ reference electrode (IQ/model ORP110-GS) and the pH measurements were performed using a combination glass electrode with a $\mathrm{Ag} / \mathrm{AgCl},[\mathrm{KCl}]=3 \mathrm{~mol} / \mathrm{l}$ reference electrode (IQ 140/model pH30-GS). Before the measurement, the $\mathrm{pH}$ and Eh probes were calibrated with buffer solution of $\mathrm{pH} 4$ and $\mathrm{pH}$ 7. $0.003 \mathrm{M}$ Potassium ferrocyanide in $0.1 \mathrm{M} \mathrm{KCl}$, and a saturated potassium chloride solution were used to store electrodes. The $\mathrm{pH}$ and Eh measurements were measured immediately in the field and before the measurement the electrode was marked at the desired depth of measurement. For this study the mark (desired depth) was $4-5 \mathrm{~cm}$. Method for measuring: The 
sediment sample was placed into a plastic container approximately at $10 \mathrm{~cm}$ depth. Measurement was conducted by carefully inserting each probe at a time to avoid disturbing the sediment as well as air contamination. Caution was taken not to have gaps between the electrode and the sediment. Start by inserting the Eh probe and wait until the reading values was quite stable which took longer time than that of the $\mathrm{pH}$ measurement and Eh values were recorded afterwards. Change to the $\mathrm{pH}$ probe for $\mathrm{pH}$ measurement and wait until the $\mathrm{pH}$ value was stable for recording.

\section{Contamination and ecological risk assessment}

Individual and global contamination factors

To study the retention of the studied elements in sediment samples, the individual contamination factors (ICF) were calculated from the results of the speciation study by dividing the sum of the first three extractions by the residual fraction for each site $^{18}$. The global contamination factor (GCF) for each site was calculated by summing the ICF obtained for the studied elements at each site ${ }^{19}$. The equation is expressed as follows:

$$
\mathrm{ICF} \text { metal }=\frac{\mathrm{C}_{\text {nonresistant }}}{\mathrm{C}_{\text {resistant }}}, \quad \mathrm{GCF}=\sum_{i=1}^{n} \mathrm{ICF}_{i},
$$

where $\mathrm{C}_{\text {nonresistant }}=$ sum of first three extractions and $\mathrm{C}_{\text {resistant }}=$ residual fraction.

In this study ICF and GCF classifications were explained as recommended by Zhao, et $\mathrm{al}^{20}$ as follows: $\mathrm{ICF}<0$ and $\mathrm{GCF}<6$ indicated low; $1<\mathrm{ICF}<3$ and $\mathrm{GCF}<12$ moderate; $3<\mathrm{ICF}<6$ and $12<\mathrm{GCF}<$ 24 considerable; and ICF $>6$ and GCF $>24$ high contamination.

\section{Risk assessment code}

Risk assessment code (RAC) is an assessment index of the risk of metal existence on the aquatic environment based on the chemical fraction of metal interaction with sediment particle which is potentially absorbed by the organisms ${ }^{21}$. Risk assessment code was obtained by calculating the percentage of exchangeable and carbonate (acid soluble) fractions in the sediment ${ }^{22}$. It is classified to be 5 classes as follows: $<1 \%$ there is no risk for aquatic system; $1-10 \%$ indicating low risk; $11-30 \%$ medium risk; $31-50 \%$ high risk; and $>50 \%$ very high risk ${ }^{23}$.
Table 2 Sediment properties and trace elements in mangrove sediment samples obtained from Songkhla Lake.

\begin{tabular}{|c|c|c|c|c|c|c|c|c|}
\hline \multirow[t]{2}{*}{ St. } & \multirow{2}{*}{$\begin{array}{c}\mathrm{pH} \\
\text { water }\end{array}$} & \multirow{2}{*}{$\begin{array}{c}\text { Salinity } \\
\text { (ppt) }\end{array}$} & \multirow{2}{*}{$\begin{array}{l}\mathrm{pH} \\
\text { sed }\end{array}$} & \multirow{2}{*}{$\begin{array}{c}\text { Eh } \\
(\mathrm{mV})\end{array}$} & As & $\mathrm{Zn}$ & $\mathrm{Cd}$ & $\mathrm{Pb}$ \\
\hline & & & & & \multicolumn{4}{|c|}{ ( $\mu \mathrm{g} / \mathrm{g}$ dry weight) } \\
\hline 1 & 9.49 & 4 & 9.00 & -17 & 33.7 & 66.3 & & 74.4 \\
\hline 2 & 9.1 & 4 & 0 & -1 & & 77 & & 79.7 \\
\hline 3 & 7.45 & 25 & 6.9 & -106 & 30 & 52 & & 56.5 \\
\hline & 7.45 & 25 & 6.9 & -106 & 14 & 34 & & 38.9 \\
\hline 5 & 7.93 & 26 & 7.27 & -200 & 58 & 104 & & 78.5 \\
\hline 6 & 7.93 & 26 & 7.27 & -200 & 50 & 10 & & 78.4 \\
\hline 7 & 7.70 & 30 & 7.21 & -206 & 34.6 & 114.3 & 0.108 & 52.1 \\
\hline 8 & 7.07 & 16 & 6.71 & -108 & 47.0 & 116.7 & 0.071 & 43.4 \\
\hline
\end{tabular}

St. $=$ Station, sed $=$ sediment.

\section{Statistical analysis}

Correlations between variables were carried out using a nonparametric test, the Spearman correlation test at the $p<0.05$ significant level. All descriptive statistical tests were performed using Microsoft Excel.

\section{RESULTS}

\section{Sediment characteristics}

The level of $\mathrm{pH}$ in water ranged from 7.07-9.49 (Table 2) while in the sediment ranged from 6.719.00. Surprisingly the highest $\mathrm{pH}$ level of sediment and water was found at Kukhut (station 1) and Ko Khob (station 2) which were located in the middle of Songkhla Lake. The high $\mathrm{pH}$ values of both sediment and water were probably caused by the waste water from cleaning the animal farms (chicken, swine, fish) surrounding these areas was drained into rivers and eventually to the Songkhla Lake since lime was commonly used as disinfection agents for cleaning the animal farms to prevent and/or treat disease outbreaks. Hence, the lime present in cleaning water of animal farms was probably responsible for the high $\mathrm{pH}$ values of sediment and water in stations 1 and 2 . Salinity ranged from 4-30 ppt. The salt water was in the outer section of the lake (stations 3-8) while low saline was found in the middle of the lake. Redox potential (Eh) value showed anoxic conditions in all stations with the maximum value at Koh Yoh (station 7).

\section{Trace metal concentration in sediments}

The range of heavy metal in $\mu \mathrm{g} / \mathrm{g}$ dry weight ranged from 14.90-58.10 for As; $34.50-116.70$ for $\mathrm{Zn}$; 0.036-0.108 for Cd; 38.9-79.0 for $\mathrm{Pb}$. The highest concentrations of As were found at the mouth of Phawong canal (stations 5 and 6) followed by Kokhob (station 2) and Ko Yoh (station 7). Zn was highest at the U-Taphao canal (station 8) followed 

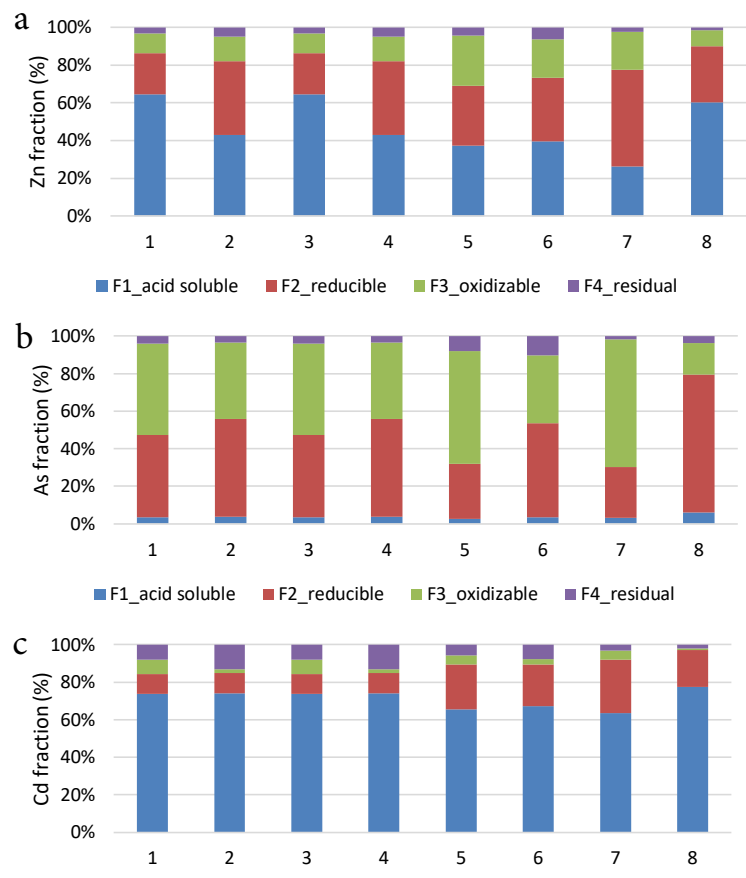

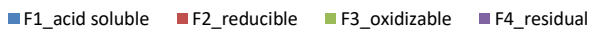

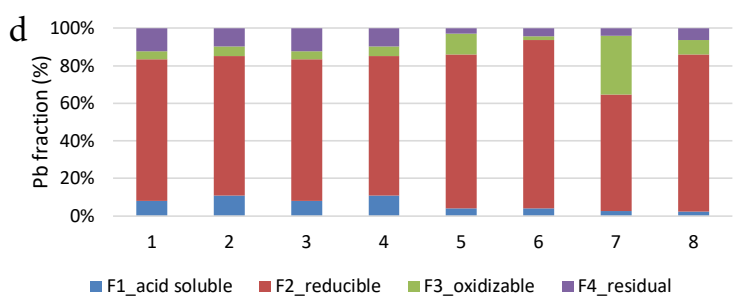

Fig. 1 (a-d) Fractionation of trace elements (Zn, As, Cd, $\mathrm{Pb}$ ) in mangrove sediments in Songkhla Lake.

by Ko Yoh (station 7) and Phawong canal (stations 5 and 6). Cd showed a similar level trend in all stations but maximum at Ko Yoh. $\mathrm{Pb}$ concentrations were highest at Ko Khob (station 2) and Phawong canal (stations 5 and 6).

\section{Element speciation}

The speciation of $\mathrm{Zn}, \mathrm{As}, \mathrm{Cd}$, and $\mathrm{Pb}$ in the mangrove sediment samples from the Songkhla Lake using the BCR protocol was presented in Fig. 1. The results of the sequential extraction for overall stations were as follows.

Exchangeable and acid soluble fraction (F1): Zn (37.20-64.42\%) and Cd (63.44-77.50\%) were found dominant in the acid-soluble fraction F1, associated with exchangeable cations and carbonates for all stations except station 7.

Reducible fraction (F2): $\mathrm{Pb}(62.01-89.48 \%)$ was found dominant in F2; As (49.92-73.45\%) was found dominant in F2 at stations 2, 4, 6, and 8. This fraction is readily available with medium mobility and may be released into the environment under unstable anoxic conditions.

Oxidizable fraction (F3): As (48.71-68.02\%) was found dominant in F3 at stations 1, 3, 5, and 7. Metals bound to organic matter are reasonably stable in nature, however, under strong oxidizing conditions such as currents, dredging, flooding and tides the organic matter can be degraded, hence leading to a release of heavy metals bound to this component ${ }^{24}$.

Residual fraction (F4): The residual solid normally consists of mainly primary and secondary minerals that retained heavy metals within their crystal structure once the first three fractions have been removed, hence, they are regarded as immobile and unavailable. This study showed percentages of residual fraction as follows; $\mathrm{Zn}$ ranged from 1.43-6.34\%, As ranged from 1.65-10.25\%, $\mathrm{Cd}$ ranged from $2.17-13.18 \%$, and $\mathrm{Pb}$ ranged from $2.88-12.30 \%$. Overall, the relative contents of trace elements in all fractions at every station were summarized as follows.

Zn: acid soluble $>$ reducible $>$ oxidizable $>$ residual;

As: oxidizable $>$ reducible $>$ residual $>$ acid soluble (at stations 2,4,6,8);

As: reducible $>$ oxidizable $>$ residual $>$ acid soluble (at stations 1,3,5,7);

Cd: acid soluble $>$ reducible $>$ residual $>$ oxidizable; $\mathrm{Pb}$ : reducible $>$ oxidizable $>$ residual $>$ acid soluble.

Fractions of $\mathrm{Cd}$ and $\mathrm{Zn}$ in every station were found to be dominant in the acid-soluble fraction (F1), associated with exchangeable cations and carbonates. The second most dominant fraction for $\mathrm{Zn}$ was the Fe-Mn oxyhydroxide fraction (F2), which might be due to the high stability constants of $\mathrm{Zn}$ oxide and the ability of Fe oxides to adsorb considerable quantities of $\mathrm{Zn}^{5}$. The As presence in samples was dominant and associated with oxidizable fraction (F3), bound to the sulphides and organic matter followed by reducible fraction (F2), associated with Fe-Mn oxyhydroxides and oxides fraction. $\mathrm{Pb}$ was dominant associated with reducible fraction (F2), associated with Fe-Mn oxyhydroxides and oxides fraction. Low abundance of $\mathrm{Pb}$ in the F1 and F4 fractions implied a low release and availability under subtoxic and natural conditions. Its abundance did not pose a threat to the sediment quality and biota. Cd was dominant with the exchangeable phase and the reducible form (F2). 
Table 3 Sediment quality guidelines (SQGs) based on its effects to benthic-dwelling species ( $\mu \mathrm{g} / \mathrm{g}$ dry weight).

\begin{tabular}{llccrc}
\hline Element & \multicolumn{3}{c}{ US EPA toxicity } & \multicolumn{2}{c}{ NOAA } \\
\cline { 2 - 6 } & None & Moderate & Heavy & ERL & ERM \\
\hline $\mathrm{Pb}$ & $<40$ & $40-60$ & $>60$ & 46.7 & 218 \\
$\mathrm{As}$ & $<3$ & $3-8$ & $>8$ & 8.2 & 70 \\
$\mathrm{Cd}$ & & & $>6$ & 1.2 & 9.6 \\
$\mathrm{Zn}$ & $<90$ & $90-200$ & $>200$ & 150 & 410 \\
\hline
\end{tabular}

$\mathrm{EPA}=$ United States Environmental Protection Agency, NOAA $=$ National Oceanic and Atmospheric Administration.

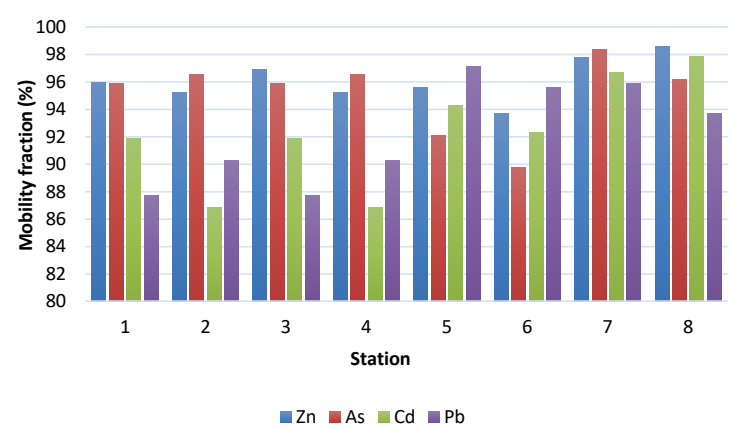

Fig. 2 Mobility fraction of trace elements in mangrove sediment in Songkhla Lake.

\section{DISCUSSION}

In order to evaluate whether the level of contamination of the sediments is due to natural or anthropogenic sources. The metal concentrations are compared with regional background values. Regional background values assessed from core sediment samples were reported by Choi, et $\mathrm{al}^{25}$ and offshore sediments in the Gulf of Thailand by Shazili, et $\mathrm{al}^{26}$. Background levels varied from 55-115 $\mu \mathrm{g} / \mathrm{g}$ dry weight for $\mathrm{Zn}$, from $5-9 \mu \mathrm{g} / \mathrm{g}$ dry weight for As, from $0.03-0.2 \mu \mathrm{g} / \mathrm{g}$ dry weight for $\mathrm{Cd}$, and from $15-30 \mu \mathrm{g} / \mathrm{g}$ dry weight for $\mathrm{Pb}$. In this study As and $\mathrm{Pb}$ concentrations were higher than those of the background values as reported by Choi, et al ${ }^{25}$. Several sediment quality guidelines (SQGs) for the assessment of the sediment quality using chemical and biological effects databases have been established. These SQGs were summarized in Table 3. NOAA presents ERL (effects range low) and ERM (effects range mean) guidelines for estuarine and marine environments which represent the 10 and 50 percentiles of adverse biological effects ${ }^{27}$. The US-EPA has also made classifications (non-polluted, moderately polluted, heavily polluted) based on toxicity tests ${ }^{28}$. Based on US-EPA, As and $\mathrm{Pb}$ were classified to be moderately polluted except stations $1,2,5$, and 6 . According to NOAA, the maximum value of As was classified as effects of mean range whereas the observed $\mathrm{Pb}$ levels was classified as effects of low range. Regarding to the expansion and industrialization of the communities surrounded the Lake, it can make a lake system receiving runoff and wastewater from the surrounding areas. Therefore, sources of pollutants introduced to the mangrove system before entering the lake system include municipal wastes from the Hat Yai and Songkhla cities, industrial wastes mainly from the rubber industries, seafood processing industries, mining activities and pollution from boats in the Songkhla harbour ${ }^{29}$.

The sequential extraction procedure employed in the study was used to assess the bioavailability of heavy metals in sediments. Bioavailability refers to the proportion of metals that can be released into the water (first three fractions). It is now widely recognized that the environmental impact by heavy metals does not simply depend on their concentrations but, critically, on their forms ${ }^{30}$. Binding forms of heavy metals to sediment particles influence the metal bioavailability ${ }^{4}$ and the forms of metals in sediments that are important to determine their ecotoxicological risk to biota ${ }^{22}$. Several authors ${ }^{22}$ have demonstrated that metals associated with the exchangeable and carbonate fractions (F1) have an anthropogenic origin, while the residual fraction (F4) corresponds to metals with a lithogenic origin ${ }^{5}$. In this study the mobility fraction $(\mathrm{F} 1+\mathrm{F} 2+\mathrm{F} 3)$ of trace elements are shown in Fig. 2. The association with the reducible fraction (F2) as the second most dominant fraction for $\mathrm{Zn}$, As, and Cd suggested that these metals played an important role in the leaching of metals into the environment. $\mathrm{Cd}$ and Zn were released mostly in the acid exchangeable step as exchangeable cations which were concordant to the result from $\mathrm{Li}$, et $\mathrm{al}^{31}$ resulting in their great bioavailability and potential risk to crops and animals. The behavior of As in natural waters depends on the $\mathrm{pH}$ and redox conditions. In oxidized sediments, arsenate $\left(\mathrm{As}^{5+}\right)$ is the dominant species, primarily bound to iron oxy-hydroxides. In reducing environments, arsenate may be reduced to the arsenite form $\left(\mathrm{As}^{3+}\right)$, which is more mobile and toxic than the arsenate form ${ }^{32}$. The outer section of the lake is thus a vulnerable area regarding the mobility of As, combining both important riverine inputs and reduced sediment conditions that promote the mobilization of As.

The potential risks of the trace elements to 
Table 4 The comparison of trace element concentrations (As, $\mathrm{Cd}, \mathrm{Pb}$, and $\mathrm{Zn}$ ) in sediments ( $\mu \mathrm{g} / \mathrm{g}$ dry weight) from Songkhla Lake and other areas.

\begin{tabular}{|c|c|c|c|c|}
\hline Area & As & $\mathrm{Cd}$ & $\mathrm{Pb}$ & $\mathrm{Zn}$ \\
\hline Songkhla Lake (Ref. 29) & $5.1-25.7$ & & & \\
\hline Songkhla Lake (Ref. 34) & $20-22$ & $0.21-0.28$ & $31-35$ & \\
\hline Songkhla Lake (Ref. 37) & 20.7 & & 55 & \\
\hline Futian, Chaina (Ref. 35) & 152.4 & & 70.7 & \\
\hline Kelantan Delta (Ref. 37) & $18.3-34.9$ & & $31.3-75.8$ & \\
\hline Punta Mala Bay, Panama (Ref. 36) & & & 78.2 & \\
\hline Pearl River, China (Ref. 31) & & $2.79-4.66$ & & $24.8-112.1$ \\
\hline Hong Kong mangrove swamps (Ref. 38) & & 3 & 80 & 240 \\
\hline Songkhla Lake (this study) & $14.9-58.1$ & $0.071-0.108$ & $38.9-79.7$ & $34.5-116.7$ \\
\hline
\end{tabular}

Table 5 Correlation coefficients $(r)$ among the total amounts of different metals and other sediment properties.

\begin{tabular}{|c|c|c|c|c|c|c|c|c|}
\hline & pHwater & Salinity & pHsed & Eh & As & $\mathrm{Zn}$ & $\mathrm{Cd}$ & $\mathrm{Pb}$ \\
\hline \multicolumn{9}{|l|}{ pHwater } \\
\hline Salinity & $-0.774^{*}$ & & & & & & & \\
\hline pHsed & $0.943^{* *}$ & $-0.755^{*}$ & & & & & & \\
\hline Eh & -0.322 & -0.207 & -0.315 & & & & & \\
\hline As & -0.024 & 0.080 & -0.077 & -0.540 & & & & \\
\hline $\mathrm{Zn}$ & -0.175 & 0.173 & -0.197 & -0.550 & $0.800^{*}$ & & & \\
\hline $\mathrm{Cd}$ & 0.321 & -0.055 & 0.316 & $-0.800^{*}$ & 0.528 & $0.777^{*}$ & & \\
\hline $\mathrm{Pb}$ & $0.714^{*}$ & -0.366 & 0.568 & -0.589 & 0.548 & 0.187 & 0.395 & \\
\hline
\end{tabular}

*, $p<0.05$ (2-tailed); ${ }^{* *}, p<0.01$ (2-tailed).

Songkhla Lake, individual and global contamination factors were calculated. The GCF is important as it reflects the overall potential risks posed by the toxic elements to the environment and biota ${ }^{33}$. Our study showed ICF $>6$ and the GC $>24$ for all elements ( $Z n$, $\mathrm{As}, \mathrm{Cd}$, and $\mathrm{Pb}$ ). For the risk assessment code, only $\mathrm{Cd}>50 \%$ in all stations was classified as very high risk for aquatic organisms whereas As was classified as low risk. Pb was classified as low risk except at stations 2 and 4 . Zn was classified as very high risk (stations 1, 3, and 8), medium risk (stations 2 , 4, and 5), and low risk (station 7) for aquatic organisms. In previous study, the increased trace metal concentration was caused by anthropogenic activities in the surrounding areas ${ }^{34}$. The result of the study of heavy metals in sediment-plant system in mangrove forest, South China Sea conducted by $\mathrm{Li}$, et $\mathrm{al}^{35}$ well agreed with our result. Furthermore, the geo-accumulation index, potential ecological risk index and risk assessment code demonstrated that heavy metals posed a considerable ecological risk, especially for cadmium (Cd).

Comparison of this study with the previous data from Songkhla Lake as well as other areas in the world is shown in Table 4. The result showed that especially the outer section of the lake, in particular the sediments at the mouths of the Phawong and U-Taphao canals and Yoh island were significantly enriched in trace elements due to municipal, agricultural and industrial discharges entering the lake through the canals. The U-Taphao and Phawong canals were important sources of $\mathrm{As}, \mathrm{Cd}$, and $\mathrm{Pb}^{34}$. Considering the data obtained from the report since $2007^{29}$, it could be observed that higher As and $\mathrm{Pb}$ concentrations in sediment were tend to increase especially in the outer section of Songkhla Lake due to urban expansion and industrialization. The maximum value of $\mathrm{Pb}$ of this study was similar to that of Punta Malala Bay, Panama ${ }^{36}$, higher than that of Fuitan, China ${ }^{33}$, but less than that of Kelantan Delta, Malaysia ${ }^{37}$. Cd and Zn concentrations from this study was lower than those in Pearl River, China and Hong Kong mangrove swamp ${ }^{31,38}$. According to the growth of the industries and the release of waste from factories and communities into the rivers, canals and mangrove forests suggested pollution from anthropogenic levels of trace metals in surface sediments. This indicated strong influence of anthropogenic processes, and diagenetic processes controlled the trace metal enrichment of core sediments of this estuary ${ }^{39}$.

The correlation among total amounts of metals 
and the environmental factors (salinity, $\mathrm{pH}$, and $\mathrm{Eh}$ ) is shown in Table 5. The close relationship between salinity and pHsed $(r=-0.755)$ and with pHwater ( $r=-0.774$ ) was observed. The total amount of $\mathrm{Pb}$ possessed the high correlation coefficient with $\mathrm{pH}$ in water $(r=0.714, p<0.05)$. Redox potential (Eh) had a close relationship with the mobility form of Cd $(r=-0.800, p<0.05)$.

In conclusion, the trace element concentrations of $\mathrm{As}$ and $\mathrm{Pb}$ in mangrove sediments of the study area were classified to be moderately to heavily polluted according to USEPA except some stations. Furthermore, sequential extraction analysis using BCR technique of mangrove sediments revealed that they were predominantly found in bioavailability forms. This is a considerable environmental concern since they represent the most labile and potentially mobile forms and readily become bioavailable. Result from ecological risk assessment found that $\mathrm{Cd}$ was very high risk for aquatic organisms. It would be the main potential risk and the sediment quality was no longer meeting the demand of the current wetland utilization strategies. Therefore it urgently needs to regularly monitor especially for $\mathrm{As}, \mathrm{Pb}$, and $\mathrm{Cd}$, since they might be harmful to the benthic organisms and finally threat to human health.

Acknowledgements: This work was financially supported by the Prince of Songkla University under contract No. COR590528S.

\section{REFERENCES}

1. Jones B, Turkie A (1997) Distribution and speciation of heavy metals in surficial sediments from the Tees Estuary, northwest England. Mar Pollut Bull 34, 768-779.

2. Andrade RA, Sanders CJ, Boaventura G, Patchineelam SR (2012) Pyritization of trace metals in mangrove sediments. Environ Earth Sci 67, 1757-1762.

3. Kumar A, Ramanathan AL (2015) Speciation of selected trace metals (Fe, $\mathrm{Mn}, \mathrm{Cu}$ and $\mathrm{Zn}$ ) with depth in the sediments of Sundarban mangroves: India and Bangladesh. J Soil Sediment 15, 2476-2486.

4. Bacon JR, Davidson CM (2008) Is there a future for sequential chemical extraction? Analyst 133, 25-46.

5. Yu R, Hu G, Wang L (2001) Speciation and ecological risk of heavy metals in intertidal sediments of Quanzhou Bay, China. Environ Monit Assess 163, 241-252.

6. Luoma SN, Rainbow PS (2008) Metal Contamination in Aquatic Environments: Science and Lateral Management, Cambridge University Press, Cambridge.

7. Gibson MJ, Farmer JG (1986) Multi-step sequential chemical extraction of heavy metals from urban soils. Environ Pollut Ser B Chem Phys 11, 117-135.
8. Ure AM, Quevauviller P, Muntau H, Griepink B (1993) Speciation of heavy metal insoils and sediments an account of the improvement and harmonisation of extraction techniques undertaken under the auspices of the BCR of the commission of the European Communities. Int J Environ Anal Chem 51, 135-151.

9. Herman P, Leeuwen V, Town RM, Buffle J, Cleven RFMJ, Daision W, Puy J, Riemsdijk WHV, et al (2005) Dynamic speciation analysis and bioavailability of metals in aquatic systems. Environ Sci Technol 39, 8545-8556.

10. Das AK, Chakraborty R, Cervera ML, Guardia M (1995) Metal speciation in solid matrices. Talanta 42, 1007-1030.

11. Sahuquillo A, Rigol A, Rauret G (2003) Overview of the use of leaching/extraction tests for risk assessment of trace metals in contaminated soils and sediments. TrAC Trends Anal Chem 22, 153-159.

12. Rauret G, Loṕez-Sańchez JF, Sahuquillo A, Rubio R, Davidson C, Ure A, Quevauviller P (1999) Improvement of the BCR three-step sequential extraction procedure prior to the certification of new sediment and soil reference materials. J Environ Monit 1, 57-61.

13. Songkhla Development Plan 2018-2021 (2019) Available at www.songkhla.go.th/news_develop_ plan. [Assessed on 24 Oct 2019]

14. Aunjangwang N (2013) Contamination of arsenic and lead in sediment of U-Taphao canal. MSc thesis, Prince of Songkla Univ, Thailand.

15. Bamrungrat N (2010) Techniques for Restoring Songkhla Lake Mangrove Forests, Prince of Songkla Univ, Thailand.

16. Meksumpun J (2003) Sediments, Department of Fishery Biology, Faculty of Fisheries, Kasetsart Univ, Thailand.

17. Noriki SK, Nakanishi T, Fukawa M, Uematsu T, Uchida S, Tsunogai (1980) Use of a Teflon vessel for the decomposition followed by the determination of chemical constituents of various marine samples. Bull Fac Fish Hokkaido Univ 31, 354-362.

18. Soliman NF, El Zokm GM, Okbah MA (2018) Risk assessment and chemical fractionation of selected elements in surface sediments from Lake Qarun, Egypt using modified BCR technique. Chemosphere 191, 262-271.

19. Ikem A, Egiebor NO, Nyavor K (2003) Trace elements in water, fish and sediment from Tuskegee Lake, Southeastern USA. Water Air Soil Pollut 149, 51-75.

20. Zhao S, Feng C, Yang Y, Niu J, Shen Z (2012) Risk assessment of sedimentary metals in the Yangtze Estuary: new evidence of the relationships between two typical index methods. J Hazard Mater 241-242, 164-172.

21. Najamuddin Prartono T, Sanusi HS, Nurjaya IW (2016) Seasonal distribution and geochemical fractionation of heavy metals from surface sediment in a 
tropical estuary of Jeneberang River, Indonesia. Mar Poll Bull 111, 456-462.

22. Sundaray SK, Nayak BB, Lina S, Bhatta D (2011) Geochemical speciation and risk assessment of heavy metals in the river estuarine sediments: a case study: Mahanadi basin, India. J Hazard Mater 186, 1837-1846.

23. Passos EA, Alves JPH (2011) Metal fractionation in the sediments for sergipe river, northeast, Brazil. $J$ Braz Chem Soc 22, 828-835.

24. MacFarlane GR, Burchett MD (2000) Cellular distribution of copper, lead and zinc in the grey mangrove, Avicennia marina (Forsk.) Vierh. Aquat Bot 68, 45-59.

25. Choi KY, Kim SH, Chon HT (2008) Distributions and accumulations of heavy metals in the sediments of harbors and coastal areas in Korea. In: Proceedings of the International Symposia on Geoscience Resources and Environments of Asian Terranes, Bangkok, Thailand, pp 474-476.

26. Shazili NAM, Rashid MKA, Husain ML, Nordin A, Ali $S$ (1999) Trace metals in the surface sediments of the South China Sea, Area I: Gulf of Thailand and East Coast of Peninsular Malaysia. In: Proceedings of the First Technical Seminar on Marine Fishery Resources Survey in the South China Sea Area I: Gulf of Thailand and East Coast of Peninsular Malaysia, Bangkok, Thailand, pp 73-85.

27. NOAA (1999) Sediment quality guidelines developed for the national status and trends program. Available at response.restoration.noaa.gov/book_shelf/ 121_sedi_qual_guide.pdf.

28. Filgueiras AV, Lavilla I, Bendicho C (2004) Evaluation of distribution, mobility and binding behaviour of heavy metals in superficial sediments of Louro River (Galicia, Spain) using chemometric analysis: A case study. Sci Total Environ 330, 115-129.

29. Sompongchaiyakul P, Sirinawin W (2007) Arsenic, chromium and mercury in surface sediment of Songkhla Lake system, Thailand. Asian J Water Environ Pollut 4, 17-24.

30. Tokalioglu S, Kartal S, Elçi L(2000) Determination of heavy metals and their speciation in lake sediments by flame atomic absorption spectrometry after a fourstage sequential extraction procedure. Anal Chim Acta 413, 33-40.

31. Li Q, Wu Z, Chu B, Zhang N, Cai S, Fang J (2007) Heavy metals in coastal wetland sediments of the Pearl River Estuary, China. Environ Pollut 149, 158-164.

32. Ryu JI, Gao S, Dahlgren RA, Zierenberg RA (2002) Arsenic distribution, speciation and solubility in shallow groundwater of Owens Dry Lake, California. Geochim Cosmochim Acta 66, 2981-2994.

33. Yao ZG, Bao ZY, Gao P, Zhang JL, Guo YP, Hu ZJ, Li BL (2006) Speciation of trace elements in sediments from Dongting Lake, central China. In: Brebbia CA, Antunes do Carmo JA (eds) Water Pollution VIII: Modelling, Monitoring and Management, WIT Press, Southampton, pp 119-128.

34. Pradit S, Gao Y, Faiboon A, Baeyens W, Leermakers M (2013) pplication of DET (diffusive equilibrium in thin films) and DGT (diffusive gradients in thin films) techniques in the study of the mobility of sediment-bound metals in the outer section of Songkhla Lake, Southern Thailand. Environ Monitor Assess 185, 4207-4220.

35. Li R, Chai M, Qiu Y (2016) Distribution fraction and ecological assessment of heavy metals in sedimentplant system in mangrove forest, South China Sea. Plos One 11, ID e0147308.

36. Defew LH, Mair JM, Guzman HM (2005) An assessment of metal contamination in mangrove sediments and leaves and from Punta Mala Bay, Pacific Panama. Mar Pollut Bull 50, 547-552.

37. Baruddin NA, Shazili NAM, Pradit S (2017) Sequential extraction analysis of heavy metals in relation to bioaccumulation in mangrove, Rhizophora mucronata from Kelantan Delta, Malaysia. AACL Bioflux 10, 172-181.

38. Tam NFY, Wong YS (2000) Spatial variation of heavy metals in surface sediments of Hong Kong mangrove swamps. Environ Pollut 110, 195-205.

39. Miola B, Morais JO (2016) Trace metal concentrations in tropical mangrove sediments, NE Brazil. Mar Pollut Bull 102, 206-209. 